PANCREATITIS

\title{
Protein tyrosine phosphatase $\kappa$ and SHP-1 are involved in the regulation of cell-cell contacts at adherens junctions in the exocrine pancreas
}

\author{
J Schnekenburger, J Mayerle, B Krüger, I Buchwalow, F U Weiss, E Albrecht, \\ V E Samoilova, W Domschke, M M Lerch
}

See end of article for authors' affiliations

Correspondence to: Professor M M Lerch, Department of Gastroenterology, Endocrinology, and Nutrition, Ernst-MoritzArndt-Universität Greifswald, FriedrichLoeffler-Strasse 23a, 17487 Greifswald, Germany; lerch@ uni-greifswald.de

Revised version received 15 March 2005

Accepted for publication 12 April 2005

Published online first

29 June 2005
Background: We have previously shown that cell contacts between pancreatic acinar cells dissociate early in pancreatitis and that this is a prerequisite for the development of pancreatic oedema. Here we studied the underlying mechanism.

Methods: Employing experimental caerulein induced pancreatitis in vivo and isolated pancreatic acini ex vivo, in conjunction with protein chemistry, morphology, and electron microscopy, we determined whether cell contact regulation in the pancreas requires or involves: (1) changes in cadherin-catenin protein expression, (2) tyrosine phosphorylation of adhesion proteins, or (3) alterations in the actin cytoskeleton. Results: During initial cell-cell contact dissociation at adherens junctions, expression of adhesion proteins remained stable. At time points of dissociated adherens junctions, the cadherin-catenin complex was found to be tyrosine phosphorylated and internalised. The receptor type protein tyrosine phosphatase (PTP) $\kappa$ was constitutively associated with the cadherin-catenin complex at intact cell contacts whereas following the dissociation of adherens junctions, the internalised components of the cadherin-catenin complex were tyrosine phosphorylated and associated with the cytosolic PTP SHP-1. In isolated acini, inhibition of endogenous protein tyrosine phosphatases alone was sufficient to induce dissociation of adherens junctions analogous to that found with supramaximal caerulein stimulation. Dissociation of actin microfilaments had no effect on adherens junction integrity.

Conclusions: These data identify tyrosine phosphorylation as the key regulator for cell contacts at adherens junctions and suggest a definitive role for the protein tyrosine phosphatases PTPK and SHP-1 in the regulation, maintenance, and restitution of cell adhesions in a complex epithelial organ such as the pancreas.
$\mathrm{E}$ ntry of fluid into the intercellular space of a given tissue is a characteristic event in the development of inflammatory oedema such as that seen in pancreatitis. While the discharge of fluid from the vasculature has been found to be a bradykinin dependent event involving the endothelium, subsequent fluid entry into the tissue clearly requires the dissociation of cell-cell contacts between individual cells of that tissue in order to occur. Cell contacts between epithelial cells are predominantly formed by proteins of the cadherincatenin family of cell adhesion proteins. The transmembrane glycoprotein E-cadherin represents the critical component of the cadherin-catenin complex forming homophilic $\mathrm{Ca}^{++}$ dependent interactions between adjacent epithelial cells via its extracellular domain. The intracellular part of E-cadherin associates with $\beta$-catenin which, in turn, binds to $\alpha$-catenin and anchors the adhesion complex to the actin cytoskeleton. ${ }^{2-5}$ An additional member of the cadherin family, pl20-catenin $\left(\mathrm{p} 120^{\mathrm{ctn}}\right)$, is thought to strengthen the adhesion complex. ${ }^{6}$ The formation of cell-cell contacts at adherens junctions must be regarded as a dynamic event, rather than a fixed structure, and undergoes extensive regulation during embryonic development and tissue repair. ${ }^{7}$

It is well established that tissue invasion of epithelial tumours of the stomach is associated with impairment of tumour cell-cell contacts caused by dysregulation of E-cadherin or changes in catenin expression..$^{8-10}$ While tumorigenesis is a comparatively slow process, which permits cell contact regulation by altering protein expression levels, the disassembly and reassembly of cell contacts during more rapid biological events such as inflammation may require different regulatory mechanisms. How the maintenance and restitution of adherens junctions in a complex epithelial organ such as the pancreas is achieved remains largely unknown but several possible mechanisms can be deduced from in vitro studies.

Cell culture experiments have shown that the functional integrity of the cadherin/catenin complex may be impaired by several principle mechanisms: firstly, if the connection between the actin cytoskeleton and the cell adhesion complex is disturbed. Such a dissociation of the actin cytoskeleton from the cadherin/catenin complex can be mediated via small GTPases which are known to indirectly regulate the polymerisation of actin microfilaments and to directly affect $\beta$-catenin binding to $\alpha$-catenin. ${ }^{11}{ }^{12}$ Furthermore, changes in the expression pattern of the components of the cadherin/ catenin complex or their level of tyrosine phosphorylation have been found to affect the function of adherens junctions. ${ }^{13}$ In $v$-src transfected cells the tyrosine phosphorylation of $\beta$-catenin correlates with a decrease in cell adhesion, ${ }^{14}{ }^{15}$ and inhibition of protein tyrosine phosphatases (PTP) has been shown to result in the tyrosine phosphorylation of $\beta$-catenin and consecutively the disassembly of cell contacts at adherens junctions. ${ }^{16}$ Protein tyrosine kinases (PTK) are known to possess constitutive basal activity that is

Abbreviations: PTP, protein tyrosine phosphatase; PTK, protein tyrosine kinase; DMEM, Dulbecco's modified Eagle's medium; SDS, sodium dodecyl sulphate; BSA, bovine serum albumin; EM, electron microscopy 
independent of ligand stimulation and it has therefore been suggested that the activity of a PTP, which would antagonise the action of PTK by dephosphorylating adhesion proteins, may be a prerequisite for the maintenance of an intact cell adhesion complex. ${ }^{17}{ }^{18}$ In cell culture and overexpression systems, a number of receptor-type PTP have been reported to be either expressed at cell-cell contacts or to use cell adhesion proteins as substrates. ${ }^{19-24}$ Both of the latter in vitro properties make PTPs likely candidates for the regulation of cell-cell contacts and prompted us to search for potential PTP binding partners of the cadherin/catenin complex in the exocrine pancreas.

To study cell contact regulation in the exocrine pancreas, a complex epithelial organ predominantly composed of polarised acinar cells, we have employed an animal model of mild experimental pancreatitis which is induced by supramaximal secretagogue stimulation and involves a reversible in vivo dissociation of adherens junctions. ${ }^{25}$ In addition, we have developed a technique to study the maintenance, and quantitate the disassembly, of cell contacts in isolated pancreatic acini, functional secretory units of between 5 and 80 cells that are prepared by collagenase digestion. ${ }^{26}$ These two approaches allowed us to study the role of cellular mechanisms in regulating the cadherin/catenin complex. Our results suggest that the dissociation of adherens junctions is paralleled by a disassembly of the cadherin/catenin complex and a redistribution of its components to the acinar cell cytosol. To distinguish between events that depend on protein tyrosine phosphorylation and those that involve impairment of the acinar cell cytoskeleton, ${ }^{27}{ }^{28}$ we studied the effect of compounds that either interfere with PTP activity or with the integrity of microfilaments. Our results indicate that a disassembly of the microfilament network does not result in dissociation of cell-cell contacts whereas inhibition of PTP activity is entirely sufficient to induce the opening of adherens junctions. Moreover, two specific PTP could be identified which, during different phases of adherens junction assembly and disassembly, can associate with the cadherin/catenin complex. These data represent the first direct evidence of a specific in vivo regulatory role of PTP in a complex epithelial organ like the exocrine pancreas.

\section{MATERIALS AND METHODS}

\section{Supramaximal secretagogue stimulation in vivo}

Male Wistar rats (140-250 g) were anaesthetised with pentobarbital $30 \mathrm{mg} / \mathrm{kg}$. A cannula was placed into the jugular vein and animals were infused with supramaximal concentrations of caerulein $(10 \mu \mathrm{g} / \mathrm{kg} / \mathrm{h}$ ) for up to 48 hours. Saline infused animals served as controls. After exsanguination under ether anaesthesia, the pancreas was rapidly removed, trimmed of fat, and tissue blocks were embedded in Tissue-Tek (Sakura Finetek, Zoeterwoude, the Netherlands) for cryosectioning. The main part of the pancreas was frozen in liquid nitrogen and stored at $-80^{\circ} \mathrm{C}$ for later protein analysis. The dry/wet weight ratio was determined as previously reported..$^{1}$ All animal experiments were conducted according to the guidelines of the local Animal Use and Care Committee, performed at least in triplicate and using a minimum of five animals unless stated otherwise in the legends.

\section{Immunoprecipitation and western blotting}

Pancreatic tissue was homogenised with a Dounce $S$ glass homogeniser (Braun, Melsungen, Germany) in iced Triton X 100 lysis buffer $(0.1 \%)$ containing protease inhibitors $(1 \mathrm{ml} /$ $\mathrm{mg}$ tissue, $10 \mu \mathrm{g} / \mathrm{ml}$ aprotinin, $10 \mu \mathrm{g} / \mathrm{ml}$ leupeptin, $0.01 \mathrm{M}$ sodium pyrophosphate, $0.1 \mathrm{M}$ sodium fluoride, $1 \mathrm{mM}$ dihydrogen peroxide, $1 \mathrm{mM}$ L-phenyl-methyl-sulfonyl-fluoride and $0.02 \%$ soybean trypsin inhibitor). Protein concentration was determined by a modified Bradford assay (Bio Rad Laboratories, München, Germany) and equal amounts of protein were used in subsequent experiments. DNA content of homogenates was determined with propidium iodide as an indicator (fluorescence reader, Ex 350 nm/Em 630 nm), was used as standard for loading equal amounts of pancreatic protein, and was used to correct for interstitial plasma protein which can be substantial when acinar cell junctions are dissociated. For immunoprecipitation, a 1:1 mixture of protein A and G Sepharose (Amersham-Pharmacia, Freiburg, Germany) was preincubated with antibody in $20 \mathrm{mM}$ HEPES pH 7.5. Lysates were preabsorbed with rat non-immun serum, added to the precoupled antibody, and incubated for two hours at $4^{\circ} \mathrm{C}$ on a rotor wheel. Precipitates were washed with HNTG-buffer (50 mM HEPES pH 7.5, $150 \mathrm{mM} \mathrm{Na} \mathrm{Cl}$, $0.1 \%$ Triton X 100, $10 \%$ glycerol) and boiled for five minutes in $2 \times$ sodium dodecyl sulphate (SDS) sample buffer. SDS polyacrylamide gel electrophoresis was performed in a discontinuous buffer system and gels were blotted on nitrocellulose membranes (Hybond C; Amersham Pharmacia). After overnight blocking in NET-gelatine ( 10 mM Tris/HCl pH 8.0, 0.15 mM NaCl, 0.05\% Tween 20, $0.2 \%$ gelatine), immunoblot analysis was performed followed by enhanced chemiluminescence detection (Amersham Pharmacia) using horseradish peroxidase coupled sheep antimouse IgG or goat antirabbit IgG (Amersham Pharmacia).

Goat antibody against РTPк and rabbit antibody against SHP-1 were obtained from Santa Cruz (Santa Cruz, California, USA). For immunostaining, a polyclonal rabbit antibody was generated against the juxtamembrane domain of РТРК (corresponding to amino acids 783-904). Monoclonal E-cadherin antibody (clone 36), directed against the carboxy terminus, was purchased from Transduction Laboratories (San Diego, California, USA) as well as antibodies against $\alpha$-, $\beta$-, and $\gamma$-catenin, and $\mathrm{p} 120^{\mathrm{ctn}}$. Antiphosphotyrosine antibody (monoclonal, 4G10) was from Upstate Biotechnology (Lake Placid, New York, USA) and polyclonal G3PDH antibody from Biozol (Eching, Germany).

For biotinylation experiments, nitrocellulose membranes were washed in $40 \mathrm{mM}$ sodium bicarbonate buffer $\mathrm{pH} 8.6$ and incubated with $5 \mu \mathrm{l}$ of biotinamidocaproate N-hydroxysuccinimidyl ester diluted in $40 \mathrm{mM}$ sodium bicarbonate buffer pH 8.6 per membrane for 15 minutes at room temperature (ECL protein biotinylation module; Amersham Pharmacia). After blocking for one hour (5\% skim milk powder), membranes were incubated with horseradish peroxidase coupled streptavidin and the signal was detected by enhanced chemiluminescence reaction (ECL; Amersham Pharmacia). For buffers and concentrations, see Fuchs and colleagues. ${ }^{20}$

\section{Immunohistochemistry}

For immunocytochemical analysis, either cryosections or paraffin sections of formaldehyde fixed rat pancreata were used. They were mounted on Polysine microslides (Menzel Gläser, Braunschweig, Germany). For antigen retrieval, deparaffinised and rehydrated sections were immersed in $10 \mathrm{mmol} / \mathrm{l}$ citric acid, $\mathrm{pH} \mathrm{6.0,}$ and boiled under pressure ( $103 \mathrm{kPa} / 15 \mathrm{psi}$ ) for two minutes. Then, cooling slides were removed, quickly washed in distilled water, and transferred to and rinsed with phosphate buffered saline. After blocking non-specific binding sites (Fc receptors) with BSA-c basic blocking solution (1:10 in phosphate buffered saline; Aurion, Wageningen, the Netherlands), sections were immunolabelled overnight at $4^{\circ} \mathrm{C}$ with antibody against PTPК (diluted l:1000), SHP-1 $(5 \mu \mathrm{g} / \mathrm{ml})$, or E-cadherin $(5 \mu \mathrm{g} / \mathrm{ml})$. G-actin was detected using Alexa Fluor 594 DNase l conjugate 
$(0.3 \mu \mathrm{m})$ and F-actin using Alexa Fluor 488 phalloidin $(0.16 \mu \mathrm{m})$, both from Molecular Probes (Eugene, Oregon, USA). Antibody labelling was subsequently detected with corresponding species specific secondary antibodies conjugated with Cy3 (Dianova, Hamburg). After counterstaining of nuclei with DAPI ( $5 \mu \mathrm{g} / \mathrm{ml}$; Sigma, St Louis, Missouri, USA) for 15 seconds, samples were mounted with Vectashield (Vector Laboratories, USA). For fluorescence microscopy, a high resolution Nikon-Improvision confocal imaging system (Watford, UK) was used. Controls were incubated without primary antibody, with mouse or rabbit $\operatorname{IgG}(5 \mu \mathrm{g} / \mathrm{ml}$; Dianova), or with pre-immune serum (1:1000) instead of primary antibody at identical concentrations. In controls, no specific immunolabelling was detected.

\section{Assessment of acinar cell contact dissociation}

Pancreatic acini from male Wistar rats (Charles River Breeding Laboratories, Sulzbach, Germany) were prepared by collagenase digestion (collagenase D; Roche, Mannheim, Germany), as previously described. ${ }^{28} 29$ Acini were washed and centrifuged at $50 \mathrm{~g}$ for one minute in Dulbecco's modified Eagle's medium (DMEM) containing $0.2 \%$ bovine serum albumin (BSA). Living acini were incubated for up to 70 minutes with buffer alone (DMEM with $0.2 \%$ BSA and $0.02 \%$ soybean trypsin inhibitor) or with buffer containing cytochalasin B (10 $\mu \mathrm{M}$; Sigma, Deisenhofen, Germany), caerulein (10 nM; Amersham Pharmacia), or orthovanadate ( $1 \mathrm{mM})$. At different intervals acini were fixed in $2 \%$ formaldehyde/2\% glutaraldehyde, embedded in Epon, and contrasted with osmium, uranyl, and lead. Ultrathin sections were used for electron microscopy. ${ }^{30}$

Alternatively, the biovolume of living acini was determined to quantitate cell contact dissociation. The concept of biovolume measurements is based on the observation that single acinar cells are smaller and accordingly displace less fluid volume than intact acini composed of multiple cells that are tightly connected by cell contacts. We established this assay using a CASY I cell analysing system (Schärfe Systems, Reutlingen, Germany). This system measures the volume of particles as resistance changes caused by electrolyte displacement during passage through an aperture of $150 \mu \mathrm{m}$ in diameter. Not unlike the principle of a FACS sorter, the diameters calculated from the obtained volumes using a standard ball formula are blotted as size frequency distributions. Phase contrast imaging of acinar cells and intact acini using fractions of defined volumes indicated that a reduction in diameter of a multi-cell acinus strictly paralleled a resolution of cell contacts and a dissociation of individual cells from the acinus. A decrease in high volume (high diameter) particles and an increase in low volume (low diameter) particles can therefore be taken as a direct indicator for the dissociation of cell contacts within an intact acinus. The system was calibrated with standard latex calibration beads (Duke Scientific Corp., Palo Alto, California, USA) of defined diameter and volume, and the composition of acini was confirmed by electron microscopy (see results). The maximum volume of acini that could readily pass the instrument's capillary was $268083 \mu^{3}$ (diameter of $80 \mu \mathrm{m}$ ) and corresponded to a mean acinus composed of the volume of 104 single cells.

For biovolume experiments, suspensions of freshly prepared acini were diluted (1:200) in filtered (particle free) physiological $\mathrm{NaCl}$ buffer. Measurements under different experimental conditions are shown for single cells (11$23 \mu \mathrm{m})$ and intact acini $(24-80 \mu \mathrm{m})$, and the results expressed as per cent of control incubations with buffer alone. The biovolume percentages shown in fig 9 are representative of six or more experiments in each group. Data show means (SD) for triplicate measurements.

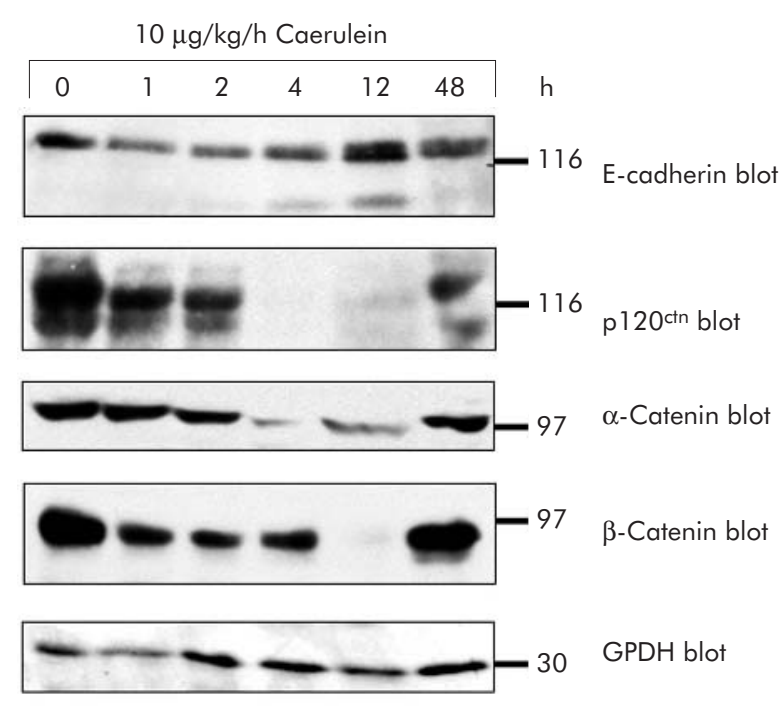

Figure 1 Expression of proteins of the cadherin/catenin complex during in vivo supramaximal secretagogue stimulation. Immunoblotting of E-cadherin, $\alpha$-catenin, $\beta$-catenin, and $\mathrm{pl} 20^{\mathrm{ctn}}$ with specific antibodies in the same sodium dodecyl sulphate-polyacrylamide gel separated Triton X 100 lysates of rat pancreatic tissue. Animals were infused with either saline or caerulein $(10 \mu \mathrm{g} / \mathrm{kg} / \mathrm{h})$ for the indicated time intervals. Lysates were standardised to $100 \mu \mathrm{g}$ protein from control pancreas. Reblotting with specific GPDH antibody demonstrated loading of equal protein amounts.

Treatment and control values at different times were tested for statistically significant differences using the Student's $t$ test. A p value of $<0.5$ was considered to be statistically significant. A raw data example of the shift in distribution from intact acini (high volume and diameter) to individual acinar cells (low volume and diameter) induced by supramaximal secretagogue stimulation is shown in fig $8 \mathrm{~B}$.

\section{PTP activity measurements in pancreatic homogenates} Untreated pancreatic homogenates $(50 \mu \mathrm{g})$ were used or alternatively protein enrichment of PTP was achieved by immunoprecipitation of pancreatic homogenates (10 mg protein immunoprecipitation). The precipitated PTP, coupled to protein A and G Sepharose beads, were incubated in PTP

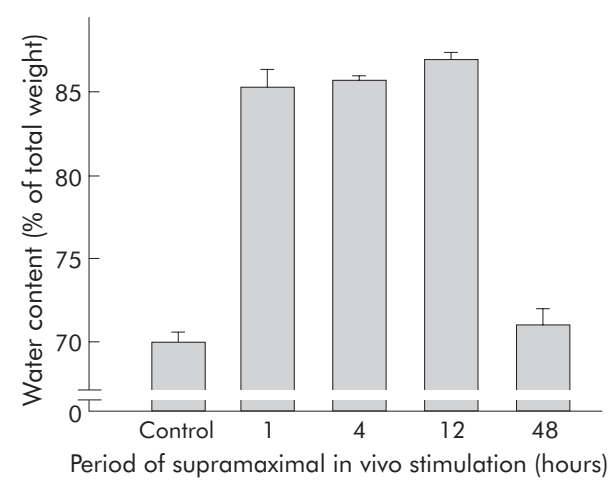

Figure 2 Interstitial pancreatic fluid collection and dissociation of cellcell contacts. As the formation of pancreatic oedema requires, and is ultrastructurally preceded by, the dissociation of cell contacts for fluid to enter the interstitial space, we determined the time course of oedema formation as an indicator of cell contact dissociation. The wet/dry weight ratio of pancreatic tissue was determined after desiccation and the results were expressed as pancreatic water content as a percentage of pancreatic weight. After 60 minutes of supramaximal caerulein infusion, entry of fluid into the pancreas was already complete and was only reabsorbed after 48 hours. 


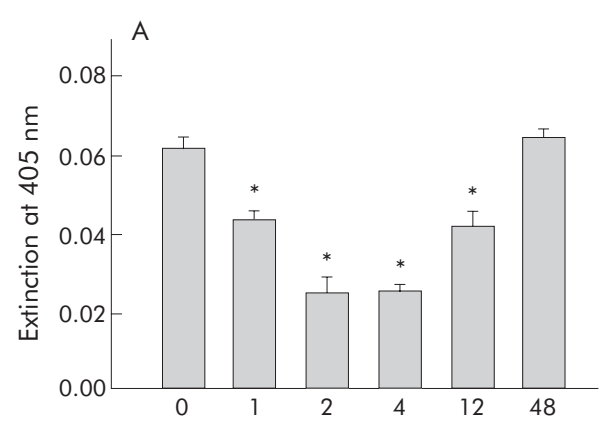

Period of supramaximal in vivo stimulation (hours)

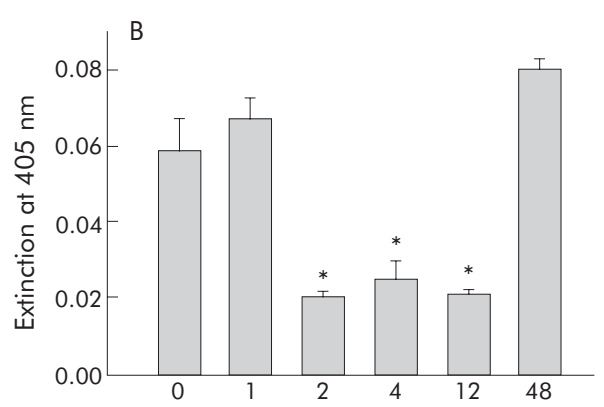

Period of supramaximal in vivo stimulation (hours)

Figure 3 Enzymatic protein tyrosine phosphatase (PTP) (A) and protein tyrosine kinase (PTK) (B) activity in caerulein induced pancreatitis. To test whether PTK and PTP possess constitutive basal activity, we used pancreatic homogenates obtained at different time points during supramaximal caerulein stimulation to measure overall enzymatic activity, as indicated in materials and methods. PTP activity was already decreased one hours after the start of caerulein infusion (A) which was paralleled by an increase in PTK activity, mainly involving src kinases (B). Interestingly, after the decrease in PTP and PTK activity during the greatest disease severity (2 and 4 hours), the increase in PTP activity was faster than that of PTK activity. *Significantly different from controls at $\mathrm{O} \mathrm{h}$.

assay reaction buffer (50 mM HEPES, $0.5 \mathrm{mM}$ EDTA, $5 \mathrm{mM}$ para-nitro-phenyl-phosphate at $\mathrm{pH} 7.0$ ) in the presence or absence of the PTP inhibitor orthovanadate ( $1 \mathrm{mM}$ ). Enzymatic activity was determined at baseline and after 30 minutes as an increase in para-nitro-phenylate using a Dynatech MR 5000 ELISA reader (405 nm).

PTK activity measurements in pancreatic homogenates To detect overall PTK activity, we used a photometric enzyme immunoassay (tyrosine kinase assay kit, non reactive, cat No 1534505; Roche Mannheim) for quantitative in vitro determination. For this a streptavidin coated microtitre plate was loaded with biotin labelled substrate (biotinKVEKIGEGTYGVVYK-amide) corresponding to amino acids 6-20 of the cell division kinase p34cdc2. This substrate displays the highest substrate specificity for the receptor associated tyrosine kinases of the src family (that is, src, yes, lck, lyn, and fyn). The assay specifically detects the activity of PTK by monitoring the transfer of the $\gamma$-phosphate group from ATP to a tyrosine residue of the biotin labelled substrate peptide. The activity can be detected via labelling with a phosphotyrosine specific peroxidase coupled antibody followed by a colour reaction (malachite green). Pancreatic homogenate $(50 \mu \mathrm{g})$ was subjected to further analysis and all experiments were performed at least in triplicates. Enzymatic activity was determined at baseline and after 60 minutes using a Dynatech MR 5000 ELISA reader $(405 \mathrm{~nm})$.
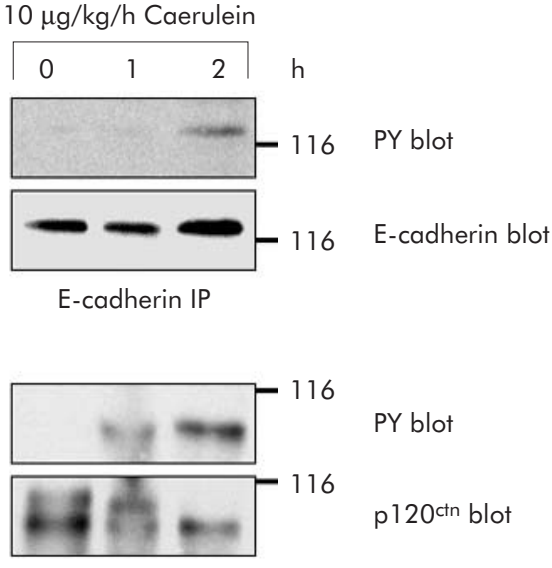

p120ctn IP
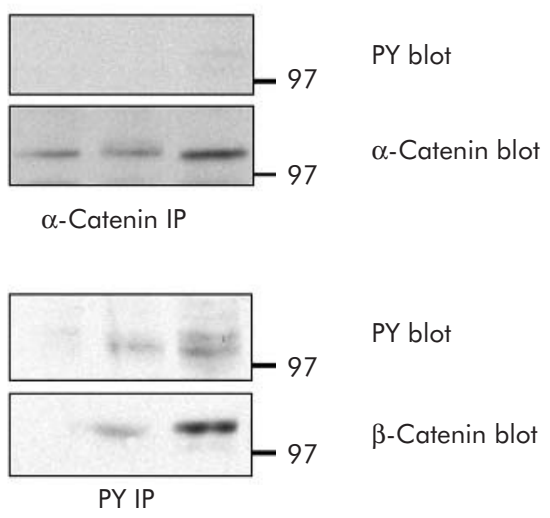

Figure 4 Time course of cadherin/catenin tyrosine phosphorylation in vivo. E-cadherin, $\alpha$-catenin, $\beta$-catenin, and $\mathrm{p} 120^{\mathrm{ctn}}$ were immunoprecipitated from pancreatic homogenates after supramaximal caerulein stimulation for the indicated time intervals. Precipitates were blotted with phosphotyrosine specific antibodies and with antibodies against E-cadherin, $\alpha$-catenin, $\beta$-catenin, and $\mathrm{p} 12 \mathrm{O}^{\mathrm{ctn}}$. Proteins were immunoprecipitated from $3 \mathrm{mg}$ pancreatic protein.

\section{RESULTS}

During the course of caerulein induced pancreatitis, a reversible in vivo dissociation of adherens junctions takes place, as indicated by a widening interstitial space on morphology (see below). To exclude reduced expression of members of the cadherin/catenin complex as being solely responsible for the dissociation of cell-cell contacts at adherens junctions, we studied protein expression of the cadherin/catenin complex during secretagogue induced disassembly of adherens junctions in vivo. In rat pancreatic homogenates obtained at different time intervals during supramaximal secretagogue stimulation (caerulein $10 \mu \mathrm{g} / \mathrm{kg}$ / h) from 0 to 48 hours, E-cadherin expression was not significantly altered over the whole time course (fig 1). Protein levels of the other components of the cadherin/catenin complex $\left(\mathrm{pl} 20^{\mathrm{ctn}}, \alpha\right.$-catenin, and $\beta$-catenin $)$ were significantly affected only at time intervals at which cell contacts had already dissociated (for example, 4 and 12 hours). This reduction in catenin levels in the later phase of the experiment is most likely due to proteolytic degradation by activated serine proteases, a characteristic event in acute pancreatitis, and was completely reversed after 48 hours. Loading of equal amounts of pancreatic homogenates was verified by blotting of G3PDH as an internal control.

On electron micrographs from rat pancreas after supramaximal caerulein infusion, dissociated adherens junctions 
could readily be detected after 30 minutes. The characteristic formation of interstitial pancreatic oedema in this animal model invariably requires, and is ultrastructurally associated with, dissociation of cell contacts. We therefore determined the time course of interstitial fluid accumulation as a surrogate marker for cell contact dissociation. ${ }^{1}$ The formation of pancreatic oedema had risen by up to one hour of supramaximal secretagogue stimulation, remained largely stable until 12 hours, and was completely resorbed by 48 hours (fig 2).

To test whether PTK and PTP possess constitutive basal activity, we studied pancreatic homogenates obtained at different time points during supramaximal caerulein stimulation. We found a marked decrease in PTP activity one hour after the start of caerulein infusion, which was paralleled by an increase in PTK activity involving mainly the family of src kinases (fig 3). Specificity for src kinases was confirmed using the biotin labelled substrate biotinKVEKIGEGTYGVVYK-amide, corresponding to amino acids 6-20 of the cell division kinase $\mathrm{p} 34^{\mathrm{cdc} 2}$ which displays the highest substrate specificity for the receptor associated tyrosine kinases of the src family (that is, src, yes, lck, lyn and fyn). These data suggested an overall increase in tyrosine phosphorylated proteins during the early phase of acute pancreatitis when cell-cell contacts dissociate (fig 3). Interestingly, after a marked decrease in PTP and PTK activity between two and four hours, recovery was somewhat faster for PTP activity than for PTK activity which could suggest that PTP activity is more critical for the reassembly of cell-cell contacts.

We subsequently studied tyrosine phosphorylation of proteins of the cadherin/catenin complex over the critical first three hours during which cell contact dissociation occurred. E-cadherin and the catenins were immunoprecipitated from pancreatic homogenates and blotted with antiphosphotyrosine specific antibodies (fig 4). While tyrosine phosphorylation of $\mathrm{pl}^{\mathrm{ctn}}$ and $\beta$-catenin was clearly detectable as early as one hour after starting secretagogue stimulation, that of E-cadherin was observed after two hours. $\alpha$-Catenin, on the other hand, did not appear to be tyrosine phosphorylated at any of the intervals investigated. An exact correlation between the time course of cell contact dissociation and tyrosine phosphorylation of cell adhesion proteins

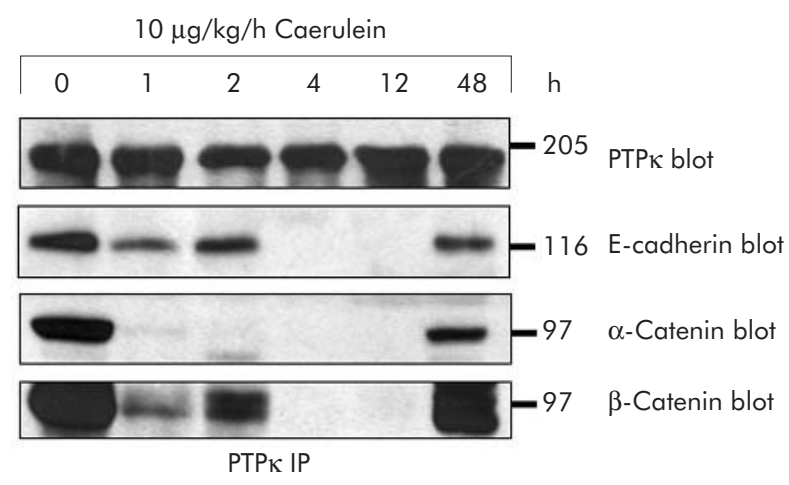

Figure 5 In vivo association of protein tyrosine phosphatase (PTP) $\kappa$ with proteins of the cadherin/catenin complex. Immunoprecipitation (IP) of PTPK from pancreatic homogenates after supramaximal caerulein stimulation for the indicated time intervals. E-cadherin, $\alpha$-catenin, and $\beta$-catenin were blotted with specific antibodies. PTPк was detected by biotinylation of membrane bound proteins and staining with horseradish peroxidase conjugated streptavidin. Biotinylation was performed as PTPк could not be reblotted when immunoprecipitated with the same antibody. Proteins were immunoprecipitated from $3 \mathrm{mg}$ pancreatic protein.

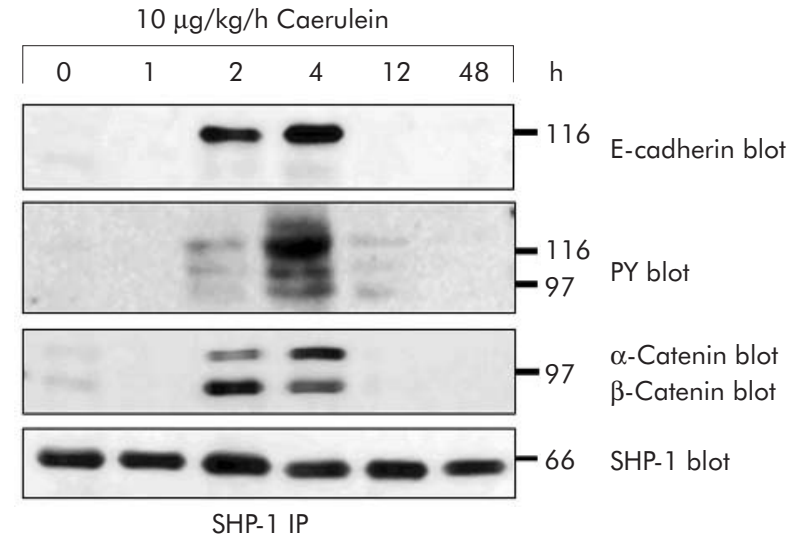

Figure 6 In vivo association of protein tyrosine phosphatase (PTP) SHP-1 with proteins of the cadherin/catenin complex.

Immunoprecipitation (IP) of PTP SHP-1 from pancreas homogenates after supramaximal caerulein stimulation for the indicated time intervals. Precipitates were blotted with antibodies against PTP SHP-1, E-cadherin, $\alpha$-catenin, $\beta$-catenin, and antiphosphotyrosine. Proteins were immunoprecipitated from $3 \mathrm{mg}$ pancreatic protein.

was thus found for $\mathrm{p} 120^{\mathrm{ctn}}$ and $\beta$-catenin. These experiments suggested that tyrosine phosphorylation in general and that of $\mathrm{p} 120^{\mathrm{ctn}}$ and $\beta$-catenin in particular are involved in the regulation of pancreatic cell contacts in vivo.

Tyrosine phosphorylation of cadherin/catenin proteins at intervals when cell contacts are dissociating suggests that PTP are involved in the maintenance of an intact cell adhesion complex at adherens junctions and we therefore sought to identify possible interacting PTP. When we studied РTPк, a member of the MAM family of transmembrane PTP whose human homologue was recently cloned, ${ }^{20}$ we found it to be constitutively associated with E-cadherin, $\alpha$-catenin, and $\beta$-catenin in the pancreas of untreated animals. As early as one hour after the onset of secretagogue stimulation, $\alpha$-catenin was found dissociated from the complex with РТР $\kappa$ and the association with E-cadherin and $\beta$-catenin was reduced (fig 5). Between four and 12 hours, on the other hand, no association between any of the adhesion proteins and РТРК could be detected. After 48 hours the complex between the adhesion proteins and PTP had entirely reassembled. None of the proteins of the cadherin/catenin complex that coprecipitated with РТРК was tyrosine phosphorylated (not shown) and expression of РTPк did not change during the course of the experiment. These experiments demonstrate a constitutive association of РTPк with the unphosphorylated cadherin/catenin complex at time intervals when adherens junctions are intact, and a dissociation of РТРк from the complex when adherens junctions are dissociated. This, in turn, strongly suggests a role for РTPк in the regulation of the activity of the complex.

If proteins of the cadherin/catenin complex have to remain dephosphorylated on tyrosine residues in order to maintain the functional integrity of adherens junctions-a mechanism that is apparently regulated by PTPк-the question arises whether they also need to be dephosphorylated to restore dissociated adherens junctions, an event in which PTPк is clearly not involved because it has already dissociated from the complex. We therefore searched for cytosolic PTP that could represent binding partners for the cadherin/catenin complex at time intervals and at subcellular sites where РTPК obviously played no role. In previous studies we and others established that the cytosolic PTP IB and PTP SHP-1 can associate with cell adhesion proteins in vitro ${ }^{31-33}$ under a variety of experimental conditions. When we studied three cytosolic PTP, we found that all of them (PTP 1B, PTP SHP-1, 

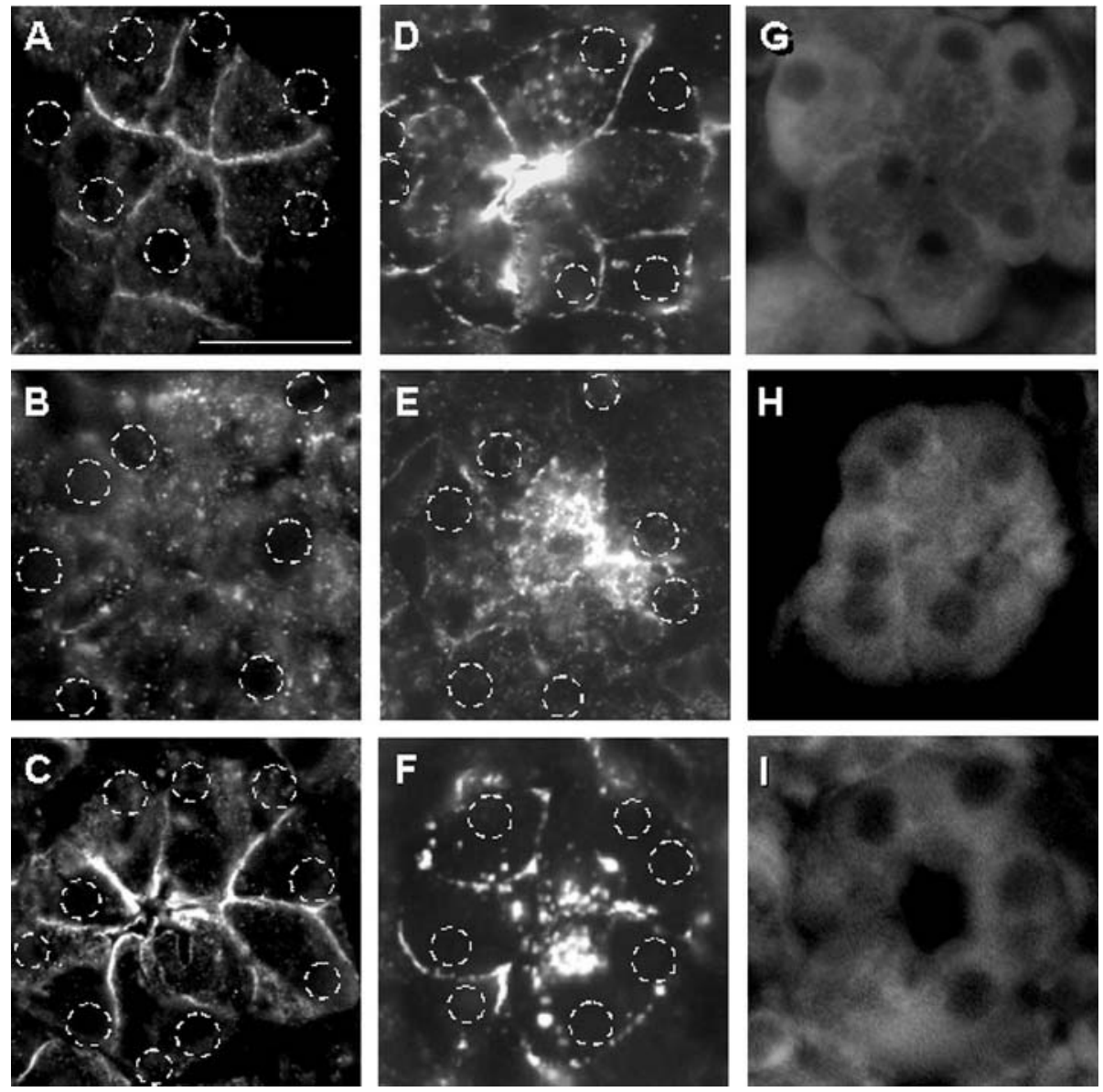

Figure 7 Localisation of protein tyrosine phosphatase (PTP) $)_{1}$ PTP SHP-1, and E-cadherin during supramaximal caerulein stimulation in vivo. Sections from pancreatic tissue after in vivo treatment with supramaximal caerulein were labelled with monospecific antibodies directed against $\mathrm{E}$-cadherin ( $A=0$ hours, $B=$ one hour, $C=48$ hours), PTPK ( $D=0$ hours, $E=$ four hours, $F=48$ hours), or PTP SHP- $1(G=0$ hours, $H=$ four hours, $I=48$ hours) and fluorescent labelled secondary antibody for confocal microscopy, as described in materials and methods. Representative acini were digitally photographed at the same contrast and brightness setting and, with the exception of the SHP-1 label, the position of nuclei as determined by the DAPI stain was marked on the respective micrographs. Bar indicates $50 \mu \mathrm{m}$.

PTP SHP-2) were expressed in the rat exocrine pancreas but neither PTP IB nor SHP-2 were associated with proteins of the cadherin/catenin complex under either control conditions or after supramaximal caerulein stimulation (not shown). PTP SHP-1 was not only consistently expressed at high levels during the entire course of supramaximal caerulein stimulation (fig 6) but also associated with adhesion proteins. This association between PTP SHP-1 and E-cadherin, $\alpha$-catenin, and $\beta$-catenin, however, was only found at two and four hours after the start of secretagogue infusion when cell-cell contacts were dissociated. Blotting with antiphosphotyrosine antibody revealed that the adhesion proteins being associated with PTP SHP-1 were all tyrosine phosphorylated. Interestingly, at the time intervals when cell contacts were morphologically intact (for example, 0 and 48 hours), no association between PTP SHP-1 and any of the cell adhesion proteins could be detected. Cytosolic PTP SHP-1, which binds tyrosine phosphorylated substrates via its $\mathrm{SH}-2$ domains, was shown to dephosphorylate the components of the cadherin/ catenin complex. ${ }^{32}{ }^{34}$ This mechanism, however, appears to be operative only when adherens junctions are dissociated and when the components or the cadherin/catenin complex are not associated with, or dephosphorylated by, РTPк. The highly complementary pattern of adhesion protein association with either PTPк or PTP SHP-l suggests that these two phosphatases may also have complementary roles in the maintenance and restitution of cell contacts.
The association of a transmembrane PTP (РTPк) and a cytosolic PTP (PTP SHP-1) with components of the cadherin/ catenin complex at different time intervals of cell contact dissociation and reassembly is not only highly suggestive of a complementary role of these phosphatases but also of a mode of action at different subcellular sites. We therefore used immunocytochemistry and confocal fluorescence microscopy to study the subcellular distribution of adhesion proteins, PTPK and PTP SHP-1. In pancreatic tissue from control rats, E-cadherin labelling was found along the area of cell-cell contacts as well as at the apical plasma membrane (fig 7A). From these sites, E-cadherin disappeared as early as one hour after the start of caerulein infusion and became evenly dispersed in a punctate pattern over the entire cytosol (fig 7B). After 48 hours, the distribution of E-cadherin at cell-cell contacts and at the acinar cell apex was completely restored (fig 7C). Localisation of РTPк under control conditions was also confined to the apical pole of the acinus and lateral cell contacts (fig 7D). During supramaximal stimulation РTPК disappeared from its original site and was redistributed to the cytoplasm, albeit at a slower rate and more concentrated at the apical part of the acinar cell than the E-cadherin label (fig 7E). Again, after 48 hours the original distribution of РТРК at adherens junctions was restored but prominent expression at the cell apex remained (fig 7F). SHP-1 was predominantly found in the basolateral cytoplasm of acinar cells with only a weak reticular label in 
the apical cell portion (fig 7G). This distribution remained unchanged during caerulein stimulation. In contrast with the E-cadherin and PTPк labels, no SHP-1 was detected at the apical pole or plasma membrane of acinar cells (fig 7H, 7I). p $120^{\mathrm{ctn}}$ and $\beta$-catenin paralleled the initial localisation and subsequent redistribution of E-cadherin (not shown). Substrate recruitment of those PTP, which are associated with members of the cadherin/catenin complex, therefore appears to be not only defined by tyrosine phosphorylation but also by subcellular localisation of adhesion proteins.

The fact that the association of PTPк and PTP SHP-1 counteracted the course of acute pancreatitis strongly suggested tyrosine phosphatase activity as the critical event
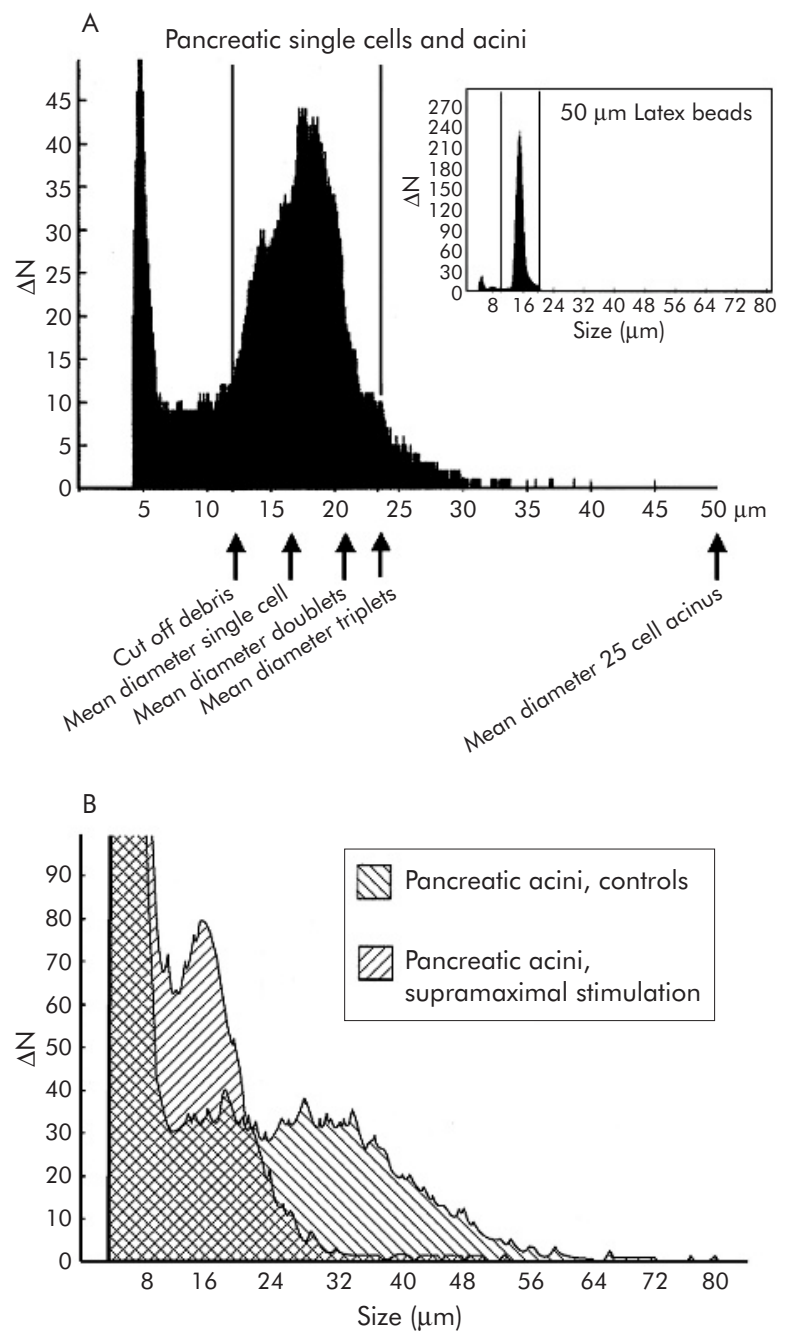

Figure 8 Dissociation of cell contacts in isolated pancreatic acini on supramaximal secretagogue stimulation. (A) Size frequency distribution of single cells in an acinar cell preparation. Single cells were prepared by a prolonged collagenase digestion. Average single cell size is calculated between the lower $(11 \mu \mathrm{m})$ and upper $(23 \mu \mathrm{m})$ diameter cut offs. Particles with diameters below $11 \mu \mathrm{m}$ are cell debris; particles above $23 \mu \mathrm{m}$ are cell aggregates of three or more cells (acini). Lower cut off, $\varnothing=11 \mu \mathrm{m}\left(\mathrm{V}=697 \mu \mathrm{m}^{3}\right)$; average single cell diameter, $\varnothing=17 \mu \mathrm{m}$ $\left(2572 \mu \mathrm{m}^{3}\right)$, acini of 25 cells, $\varnothing=50 \mu \mathrm{m}\left(65450 \mu \mathrm{m}^{3}\right)$. Insert: Size distribution of standard latex beads with an average diameter of $15 \mu \mathrm{m}$ (Duke Scientific Corporation, Palo Alto, California, USA). (B) Overlay of size distribution of a culture of pancreatic acini before and 30 minutes after stimulation with a supramaximal concentration of caerulein $(10 \mathrm{nM})$. There is a shift from complex acini (aggregates above the upper cut off of $23 \mu \mathrm{m}$ ) to single acinar cells (cells with diameters between $11 \mu \mathrm{m}$ and $23 \mu \mathrm{m}$ ) caused by the caerulein induced disintegration of cell-cell contacts. in the regulation of cell-cell contacts at adherens junctions. In order to study different mechanisms that could be involved in the regulation of adherens junctions, we established an assay to study cell contact dissociation of freshly isolated acini from rat pancreas as a reductionist in vivo model. This model allowed us to investigate the effect of a single stimulus with regard to signalling events. Our assay is based on the observation that disintegration of cell-cell contacts on supramaximal secretagogue stimulation permits individual cells to dissociate from their original acinus. The biovolume of the intact acinus (between 5 and 100 cells or equivalent to a sphere with a diameter of 24-80 $\mu \mathrm{m}$ ) decreases when cell contacts dissociate while, simultaneously, the biovolume proportion of individual single cells (mean diameter $17 \mu \mathrm{m}$, range $11-23 \mu \mathrm{m}$ ) increases. When we calibrated this system with standard latex calibration beads of defined diameter and volume (inset in fig 8A) and confirmed the composition of acini by electron microscopy, we found that single acinar cells have a mean cellular biovolume of $2572 \mu \mathrm{m}^{3}$ (fig 8A), corresponding to a calculated diameter of $17 \mu \mathrm{m}$. In order to discriminate the biovolume of acinar cells from microscopically identified cellular debris, a cut off volume of $697 \mu \mathrm{m}^{3}$ was set which corresponds to a diameter of $11 \mu \mathrm{m}$ and thus $25 \%$ of an average acinar cell. Multi-cell acini, as opposed to single acinar cells, consistently had a volume of $6370 \mu \mathrm{m}^{3}$ (diameter of over $23 \mu \mathrm{m}, 2.5$-fold the mean single cell volume) and all particles of greater volume were subsequently defined as acini. The maximum volume of acini that could readily pass the instrument's capillary was $268083 \mu \mathrm{m}^{3}$ (diameter of $80 \mu \mathrm{m}$ ) and corresponded to a mean acinus composed of 104 single cells. A raw data example of the shift in distribution from intact acini (high volume and diameter) to individual acinar cells (low volume and diameter) induced by supramaximal secretagogue stimulation is shown in fig $8 \mathrm{~B}$.

In parallel, we studied cell contacts of incubated acini by electron microscopy (EM). During control incubation of acini over 70 minutes in buffer alone, neither the proportion of single cells (fig 9A, left panel) nor the number of intact acini (fig 9A, centre panel) changed. Morphologically, isolated acini contained abundant zymogen granules at the apical pole and cell contacts between adjacent cells remained intact (fig 9A, right panel). Inhibition of PTP activity by $1 \mathrm{mM}$ orthovanadate dissociated adherens junctions, increased the numbers of single cells (fig 9C, left panel), and decreased the proportion of intact acini (fig 9C, centre panel). Interestingly, remaining cell contacts in these acini were mostly found at the site of tight junctions close to the acinar lumen, as evaluated by electron microscopy (arrow in fig 9C, right panel). Tight junctions may therefore be regarded as more resistant to PTP inhibition than other types of cell contacts. The orthovanadate concentration used here has been previously shown to have no toxic effect on cultured cells. ${ }^{35}$ We also found it to inhibit approximately $70 \%$ of РTPк activity and approximately $75 \%$ of PTP SHP-1 activity in an assay using immunoprecipitates for PTP $\kappa$ and PTP-SHP-1 from untreated rat pancreatic homogenates by pNPP assay. Incubation with supramaximal caerulein concentrations induced the dissociation of adherens junctions between pancreatic acinar cells slightly faster than PTP inhibition alone (fig 9B, right panel), as reflected by a more rapid increase in single cell biovolume (fig 9B, left panel) and a more rapid decline in intact acini (fig 9B, centre panel). The observed dissociation of cell contacts in isolated acini is comparable with previous results obtained with supramaximal secretagogue infusion in rodents. ${ }^{25}$ Surprisingly, incubation with the microfilament depolymerising agent cytochalasin B ( $10 \mu \mathrm{M})$, which has been shown to completely disrupt the actin cytoskeleton in pancreatic acinar cells, ${ }^{36}$ had 

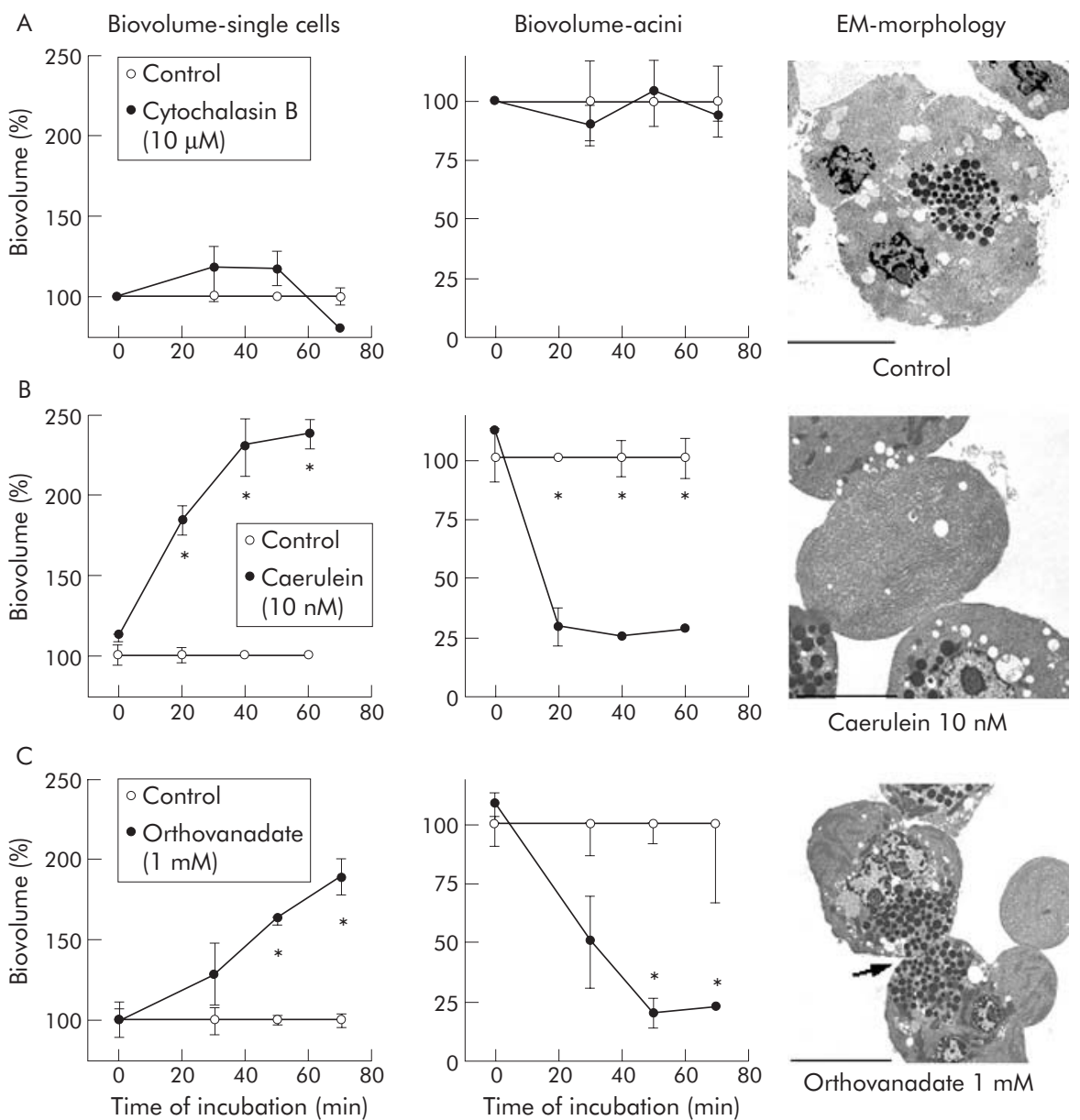

Figure 9 Dissociation of cell contacts in isolated pancreatic acini after protein tyrosine phosphatase (PTP) inhibition. The integrity of cell contacts in isolated pancreatic acini was evaluated as changes in the isovolume of the single cells fraction (left panels) or the intact acini fraction (centre panels), and the corresponding electron micrographs (EM) are shown in the right panels. Data are expressed as per cent of untreated controls for acini after treatment with cytochalasin $B(10 \mu \mathrm{M}$, row $A)$, supramaximal caerulein $\left(10^{-8} \mathrm{M}\right.$, row $\left.\mathrm{B}\right)$, or $1 \mathrm{mM}$ orthovanadate (row $\left.\mathrm{C}\right)$ for up to 70 minutes. *Significant differences from respective control values $(p<0.05)$. Bars indicate $20 \mu \mathrm{m}$.

no effect on the proportion of single cells versus intact acini (fig 9A, left and centre panel).

To confirm that the effect of cytochalasin is due to its microfilament disrupting action we first labelled intact acini for G-actin and F-actin (fig 10A), which localised F-actin firmly to cell-cell contacts and the acinar lumen (fig 10A, 10B). Cytochalasin not only induced a rapid distribution of F-actin from the cell contacts to the cytosol (fig 10C) but also greatly reduced stimulated pancreatic secretion (fig 10D).

Our study therefore shows that maintenance of acinar cell adherens junctions is independent of an intact actin microfilament network, is a regulated process for which tyrosine phosphorylation of members of the cadherin/catenin family is critical, and in which the activity of РTPК and РTP SHP-1-at distinct intervals and at specific subcellular sitesplays an important role.

\section{DISCUSSION}

While most of our knowledge about the components of cell adhesions has been obtained from cell culture experiments and overexpression systems, information about regulation of cell-cell contacts in complex epithelial organs is sparse. To study the regulation of cell adhesions under controlled experimental conditions and in vivo, we employed an animal model of experimental pancreatitis. Three likely mechanisms of cadherin/catenin complex regulation were analysed. We first studied protein expression of the cadherin/catenin complex during the secretagogue induced disassembly of adherens junctions. Secretagogue stimulation in vivo had only minor effects on protein expression of E-cadherin over the entire 48 hour course of dissociation and reassembly of cell adhesions. All four catenins, on the other hand, were found at lower protein levels than in controls, between two and 12 hours of caerulein infusion, and we believe this effect to be due to intracellular proteolytic degradation by activated digestive enzymes. ${ }^{37}$ The caerulein mediated dissociation of cell-cell contacts and formation of pancreatic oedema was almost complete within one hour, as indicated by a rapid increase in the wet/dry weight ratio and only a slight increase could be monitored from one to 12 hours. The rapid increase suggests not only involvement of cell-cell contacts at epithelial adherens junctions but also involvement of endothelial junctions. E-cadherin forms the extracellular part of the paracellular barrier and it has been previously suggested that cell-cell contacts at endothelial adherens junctions could also be regulated by tyrosine phosphorylation. ${ }^{38}{ }^{39}$ However, in our experimental setting during this initial period of cell contact dissociation, all proteins of the cadherin/catenin complex remained stably expressed at control levels. Alterations in cadherin/catenin protein levels could therefore be excluded as a triggering event for cell dissociation following supramaximal secretagogue stimulation. 

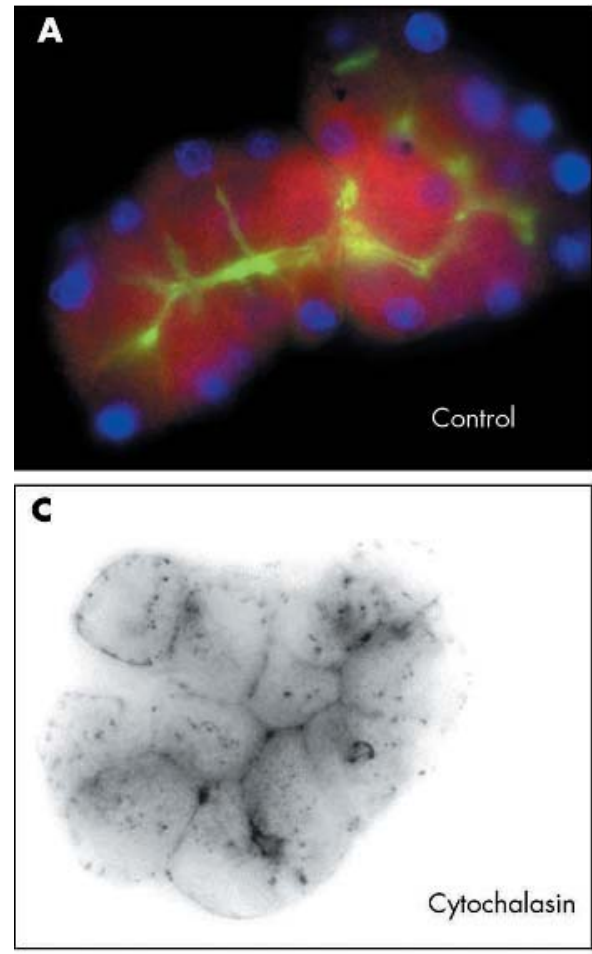

B
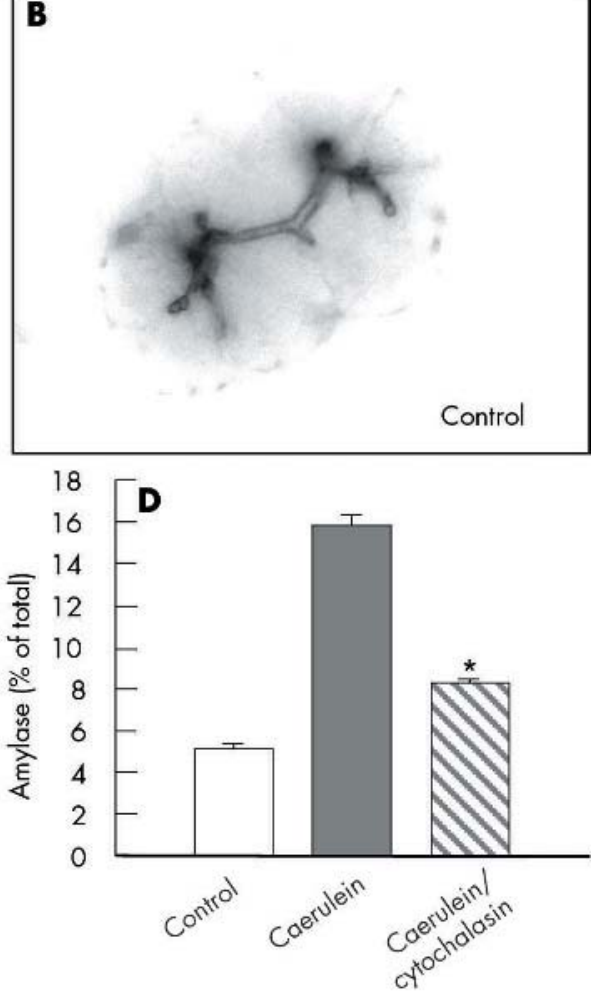

Figure 10 Effect of cytochalasin on the cytoskeleton of pancreatic acini. To evaluate the effect of cytochalasin on microfilament disruption, untreated intact acini were labelled for G-actin (red) and F-actin (green) (A), which localised F-actin firmly to cell-cell contacts and the acinar lumen and G-actin to the cytosol (A, B). Incubation of acini with cytochalasin (10 $\mu \mathrm{M}, 40$ minutes) caused not only rapid distribution of F-actin from cell contacts to the cytosol (C) but also greatly reduced stimulated pancreatic secretion (D).

Secondly, in our in vivo studies, we investigated tyrosine phosphorylation as a regulator of cell contact regulation. In these experiments involving immunoprecipitation adhesion proteins of the cadherin/catenin complex were found to be phosphorylated on tyrosine residues in vivo and in addition we detected an imbalance of PTP and PTK activity in the early phase of pancreatitis, indicating involvement of protein tyrosine phosphorylation in the regulation of cell-cell contacts. Shortly after the start of supramaximal caerulein infusion, $\beta$-catenin and $\mathrm{pl} 20^{\mathrm{ctn}}$ were tyrosine phosphorylated in a manner that paralleled the time course of cell contact dissociation whereas tyrosine phosphorylation of E-cadherin could only be detected after cell contacts had already dissolved. Although the physiological function of E-cadherin phosphorylation has not been completely elucidated, an E-cadherin- $\alpha$-catenin fusion chimera which connects the complex to the actin cytoskeleton, without the presence or involvement of $\beta$-catenin, has been reported to undergo regulation by the tyrosine kinase $v$-src. ${ }^{40}{ }^{41}$ Whether or not $\alpha$-catenin can be physiologically tyrosine phosphorylated is still a matter of debate and the evidence in the literature is conflicting. Our data would suggest that a small portion of the $\alpha$-catenin pool is indeed tyrosine phosphorylated and that this portion can be coimmunoprecipitated with and is associated with PTP SHP-1 (PTP SHP-1 only recognising phosphorylated proteins). On the other hand, this portion is too small to be detected by PY blotting if $\alpha$-catenin is immunoprecipitated. Nevertheless, in our physiological and endogenous system, the main pool of $\alpha$-catenin was not found to be tyrosine phosphorylated. We therefore conclude that the functional regulation of the cadherin/ catenin complex by tyrosine phosphorylation predominantly involves $\mathrm{p} 120^{\mathrm{ctn}}$ and $\beta$-catenin, as has previously been suggested for in vitro systems. ${ }^{20} 3242$ Tyrosine phosphorylation of $\beta$-catenin can thus be regarded as a major switch in the link between membrane bound E-cadherin and the actin cytoskeleton. ${ }^{1415}$

After we had identified tyrosine phosphorylation as a possible driving force for the control of pancreatic acinar cellcell contacts, we searched for proteins that would be involved in the regulation of this process. We predicted that specific PTP would keep the cell adhesion complex in its dephosphorylated and thus in its active state while cell contacts remain intact. Since we and others had identified transmembrane PTP of the MAM family-including РTPК—at the cell adhesions of cultured epithelial cells and in association with members of the cadherin/catenin complex in vitro, ${ }^{19} 2024{ }^{43}$ we considered them the most promising candidates. Under resting conditions, РТРК was found to associate constitutively with the cadherin/catenin complex when the latter was not tyrosine phosphorylated. РТРк rapidly dissociated from the adhesion complex at intervals when cell contacts were disassembled following supramaximal secretagogue stimulation. Interestingly, $\alpha$-catenin, which is the direct link of the adhesion complex to the actin cytoskeleton, was the first adhesion protein to lose its association with РTPк. This finding is in accordance with the recent observation that the tyrosine phosphorylation of $\beta$-catenin can induce rapid dissociation of $\alpha$-catenin from the cadherin/catenin complex. ${ }^{16}$ РТPк thus appears to represent an integral and functional component of the cell adhesion complex in epithelial cells. Its role appears to involve the stabilisation of adherens junctions by continuous dephosphorylation of the cadherin/catenin complex. This function could be supported by the formation of homophilic PTPК interactions via its extracellular MAM domain. ${ }^{44} 45$ 
Surprisingly, the time course of association and dissociation between cell adhesion proteins and PTP SHP-1 is almost the opposite of that with РТРк. РTP SHP-1, which was recently found to regulate $\mathrm{pl} 20^{\mathrm{ctn}}$ in vitro, ${ }^{32}$ is expressed in various epithelial cells and its substrate recruitment involves phosphotyrosine binding SH-2 domains. ${ }^{46}{ }^{47}$ We found that SHP-1 associates with tyrosine phosphorylated cell adhesion proteins only after their internalisation away from the cell surface. PTP SHP-1 could therefore play a physiological role in the restitution of pancreatic acinar cell adherens junctions.

The highly complementary manner in which РTРк and SHP-1 recruit their binding partners among adhesion proteins during the dynamic cell contact dissociation and restitution in vivo cannot be solely explained by the tyrosine phosphorylation status of their respective substrates alone. Another requirement for the interaction between PTP and substrate adhesion proteins should involve their localisation at the same time interval at the same intracellular site. Our immunolocalisation experiments indicated a strictly cytoplasmic expression of PTP SHP-1 during all intervals of the experiment. It was interesting to note that a more prominent cytosolic PTP SHP-1 localisation was found in the basolateral portion of acinar cells and the labelling spared the apical pole. In contrast, E-cadherin and the catenins were found at the acinar cell membrane and rapidly and evenly redistributed to the cytosol only after supramaximal caerulein stimulation. Labelling for РТРк was even more restricted to adherens junctions and its redistribution to the cytosol was slower $(4 \mathrm{v}$ 1 hour) and more concentrated to the apical portion of the cells than that of E-cadherin after secretagogue stimulation. These data indicate that the subcellular localisation of either the adhesion protein substrates or their PTP binding partners is essential for PTP substrate recruitment. After 48 hours, not only had junctional integrity but also the original localisation of PTP and adhesion proteins been largely restored. This suggests that the subcellular relocalisation and redistribution of cadherin/catenin complex proteins during supramaximal stimulation is not only a dynamic but also a highly regulated process.

Recent studies supported a concept of increased tyrosine phosphorylation of members of the cadherin/catenin complex as an inducer of the internalisation into the cytoplasm combined with loss of a $\beta$-catenin-cytoskeletal association. ${ }^{48}$ Regulated internalisation of E-cadherin in epithelial cells was shown to occur by clathrin independent endocytosis. ${ }^{49}$

The data obtained from our experiments support direct involvement of protein tyrosine phosphorylation as the mechanism that regulates cell-cell contacts at adherens junctions in vivo.

To reduce the parameters that can affect our in vivo model, we developed a less complex ex vivo assay to study the effect of a defined signal for the dissociation of cell contacts in pancreatic acini. Isolated pancreatic acini resemble an in vivo model, and represent functional secretory units of living primary exocrine cells, in which cells maintain their polarised phenotype, respond to hormone stimulation, retain their stimulus secretion coupling, and possess intact cell-cell adhesions, including tight, GAP, and adherens junctions. ${ }^{50} 51$ We freshly prepared these acini by collagenase digestion from rodent pancreas ${ }^{29}{ }^{52}$ and studied the disassembly of their cell contacts under controlled conditions. As we previously reported in vivo, ${ }^{25}$ administration of supramaximal cholecystokinin (or its analogue caerulein) induced rapid dissociation of cell contacts and led to continuous disintegration of the intact acinus into individual single cells. Interestingly, incubation of acini with the specific PTP inhibitor orthovanadate had the same effect on the integrity of cell junctions and dissociated intact acini into individual cells. This establishes that inhibition of PTP activity alone is entirely sufficient to dissociate acinar cell-cell contacts and strongly confirms involvement of tyrosine phosphorylation in their regulation. As supramaximal secretagogue stimulation is also known to disassemble the acinar cell cytoskeleton, ${ }^{27}$ we tested whether depolymerisation of the actin microfilament network by cytochalasin B would also be sufficient to dissociate cell adhesion. It was not; at concentrations that block actin dependent exocytosis and lead to actin redistribution, ${ }^{53}$ cytochalasin B had no effect on the integrity of cell-cell contacts or the integrity of acini. These experiments clearly establish that pancreatic adherens junctions are regulated by mechanisms that involve protein tyrosine phosphorylation and dephosphorylation but are independent of the assembly or depolymerisation of the actin cytoskeleton.

While it is known that proteins of the cadherin/catenin complex participate in embryonic development, tissue morphogenesis, and malignant tumour invasion, their role in the rapid assembly and disassembly of epithelial cell-cell contacts is less clear. Our present data suggest that tyrosine phosphorylation of cell adhesion proteins plays a critical role in regulating the formation, maintenance, and reassembly of the cadherin/catenin complex and of cell-cell contacts in vivo. They further establish that depolymerisation of the actin cytoskeleton will not directly interfere with the preservation of intact cell adhesion, and that the activity of PTP-and specifically an association of adhesion proteins with РTPк and PTP SHP-1-are critical elements in the control of cell contact regulation. Particularly the latter process appears to be closely regulated and depends not only on substrate specificity but also on the dynamic subcellular localisation of the proteins involved. Moreover, our data represent the first experimental evidence of direct involvement of tyrosine phosphorylation and dephosphorylation of cell adhesion proteins in the regulation of cell-cell contacts of a complex epithelial organ such as the exocrine pancreas.

\section{ACKNOWLEDGEMENTS}

The work presented was supported by grants from the Deutsche Forschungsgemeinschaft (MML and BK), the BMBF (IZKF Münster to JS and MML), and the Deutsche Krebshilfe Mildred-ScheelStiftung (to MML and JM).We wish to thank U Breite, M Hülsbusch, U Naumann, and S Rackow for expert technical assistance.

\section{Authors' affiliations \\ J Schnekenburger", I Buchwalow, V E Samoilova, W Domschke, Department of Medicine B, Westfälische Wilhelms-Universität Münster, Münster, Germany \\ J Mayerle*, F U Weiss, M M Lerch, Department of Gastroenterology, Endocrinology, and Nutrition, Ernst-Moritz-Arndt-Universität Greifswald, Greifswald, Germany \\ B Krüger, E Albrecht, Department of Pathology, Division of Medical Biology, Universität Rostock, Rostock, Germany}

*J Schnekenburger and J Mayerle contributed equally to this paper. Conflict of interest: None declared.

\section{REFERENCES}

1 Lerch MM, Weidenbach $\mathrm{H}$, Gress TM, et al. Effect of kinin inhibition in experimental acute pancreatitis. Am J Physiol 1995;269:G490-9.

2 Hinck L, Nathke IS, Papkoff J, et al. Dynamics of cadherin/catenin complex formation: novel protein interactions and pathways of complex assembly. J Cell Biol 1994; 125:1327-40.

3 Ozawa M, Baribault H, Kemler R. The cytoplasmic domain of the cell adhesion molecule uvomorulin associates with three independent proteins structurally related in different species. Embo $\mathrm{J}$ 1989;8:1711-17.

4 Rimm DL, Koslov ER, Kebriaei P, et al. Alpha 1(E)-catenin is an actin-binding and -bundling protein mediating the attachment of F-actin to the membrane adhesion complex. Proc Natl Acad Sci U S A 1995;92:8813-17.

5 Yap AS, Brieher WM, Gumbiner BM. Molecular and functional analysis of cadherin-based adherens junctions. Annu Rev Cell Dev Biol 1997; 13:1 19-46. 
6 Thoreson MA, Anastasiadis PZ, Daniel JM, et al. Selective uncoupling of p120(ctn) from E-cadherin disrupts strong adhesion. J Cell Biol 2000;148:189-202

7 Gumbiner BM. Cell adhesion: the molecular basis of tissue architecture and morphogenesis. Cell 1996;84:345-57.

8 Guilford P, Hopkins J, Harraway J, et al. E-cadherin germline mutations in familial gastric cancer. Nature 1998;392:402-5.

9 Perl AK, Wilgenbus P, Dahl U, et al. A causal role for E-cadherin in the transition from adenoma to carcinoma. Nature 1998;392:190-3.

10 Behrens J. Cadherins and catenins: role in signal transduction and tumor progression. Cancer Metastasis Rev 1999;18:15-30.

11 Braga VM, Machesky LM, Hall A, et al. The small GTPases Rho and Rac are required for the establishment of cadherin-dependent cell-cell contacts. J Cell Biol 1997; 137:1421-31.

12 Fukata $M$, Nakagawa $M$, Kuroda $S$, et al. Cell adhesion and Rho small GTPases. J Cell Sci 1999; 1 12:4491-500.

13 Gumbiner BM. Regulation of cadherin adhesive activity. J Cell Biol 2000; 148:399-404

14 Matsuyoshi N, Hamaguchi M, Taniguchi S, et al. Cadherin-mediated cell-cell adhesion is perturbed by $\mathrm{v}$-src tyrosine phosphorylation in metastatic fibroblasts. J Cell Biol 1992;118:703-14.

15 Behrens J, Vakaet L, Friis R, et al. Loss of epithelial differentiation and gain of invasiveness correlates with tyrosine phosphorylation of the E-cadherin/betacatenin complex in cells transformed with a temperature-sensitive v-SRC gene. J Cell Biol 1993; 120:757-66.

16 Ozawa M, Kemler R. Altered cell adhesion activity by pervanadate due to the dissociation of alpha-catenin from the E-cadherin.catenin complex. J Biol Chem 1998;273:6166-70.

17 Muller T, Choidas A, Reichmann E, et al. Phosphorylation and free pool of beta-catenin are regulated by tyrosine kinases and tyrosine phosphatases during epithelial cell migration. J Biol Chem 1999;274:10173-83.

18 Zondag GC, Moolenaar WH. Receptor protein tyrosine phosphatases: involvement in cell-cell interaction and signaling. Biochimie 1997:79:477-83.

19 Brady-Kalnay SM, Rimm DL, Tonks NK. Receptor protein tyrosine phosphatase PTPmu associates with cadherins and catenins in vivo. J Cell Biol 1995; 130:977-86.

20 Fuchs M, Muller T, Lerch MM, et al. Association of human protein-tyrosine phosphatase kappa with members of the armadillo family. J Biol Chem 1996;271:16712-19.

21 Kypta RM, Su H, Reichardt LF. Association between a transmembrane protein tyrosine phosphatase and the cadherin-catenin complex. J Cell Biol 1996:134:1519-29.

22 Wang $\mathrm{H}$, Lian Z, Lerch MM, et al. Characterization of PCP-2, a novel receptor protein tyrosine phosphatase of the MAM domain family. Oncogene 1996; 12:2555-62.

23 Aicher B, Lerch MM, Muller T, et al. Cellular redistribution of protein tyrosine phosphatases LAR and PTPsigma by inducible proteolytic processing. J Cell Biol 1997; 138:681-96.

24 Zondag GC, Reynolds AB, Moolenaar WH. Receptor protein-tyrosine phosphatase RPTPmu binds to and dephosphorylates the catenin p120(ctn). $J$ Biol Chem 2000;275:11264-9.

25 Lerch MM, Lutz MP, Weidenbach $\mathrm{H}$, et al. Dissociation and reassembly of adherens junctions during experimental acute pancreatitis. Gastroenterology 1997; 113:1355-66

26 Kruger B, Albrecht E, Lerch MM. The role of intracellular calcium signaling in premature protease activation and the onset of pancreatitis. Am J Pathol 2000;157:43-50.

27 Jungermann J, Lerch MM, Weidenbach $\mathrm{H}$, et al. Disassembly of rat pancreatic acinar cell cytoskeleton during supramaximal secretagogue stimulation. Am J Physiol 1995;268:G328-38.

28 Lerch MM, Saluja AK, Dawra R, et al. The effect of chloroquine administration on two experimental models of acute pancreatitis. Gastroenterology 1993; 104:1768-79

29 Williams JA, Korc M, Dormer RL. Action of secretagogues on a new preparation of functionally intact, isolated pancreatic acini. Am J Physiol 1978;235:517-24.
30 Lerch MM, Saluja AK, Runzi M, et al. Luminal endocytosis and intracellular targeting by acinar cells during early biliary pancreatitis in the opossum. J Clin Invest 1995;95:2222-31.

31 Balsamo J, Arregui $C$, Leung $T$, et al. The nonreceptor protein tyrosine phosphatase PTP1B binds to the cytoplasmic domain of $\mathrm{N}$-cadherin and regulates the cadherin-actin linkage. J Cell Biol 1998;143:523-32.

32 Keilhack $\mathbf{H}$, Hellman $U$, van Hengel J, et al. The protein-tyrosine phosphatase SHP-1 binds to and dephosphorylates p1 20 catenin. J Biol Chem 2000;275:26376-84.

33 Schnekenburger J, Mayerle J, Simon P, et al. Protein tyrosine dephosphorylation and the maintenance of cell adhesions in the pancreas. Ann N Y Acad Sci 1999;880:157-65.

34 Duchesne $\mathrm{C}$, Charland S, Asselin C, et al. Negative regulation of beta-catenin signaling by tyrosine phosphatase SHP-1 in intestinal epithelial cells. J Biol Chem 2003;278:14274-83

35 Cortizo AM, Salice VC, Vescina CM, et al. Proliferative and morphological changes induced by vanadium compounds on Swiss 3 T3 fibroblasts. Biometals 1997; 10:127-33.

36 O'Konski MS, Pandol SJ. Cholecystokinin JMV-180 and caerulein effects on the pancreatic acinar cell cytoskeleton. Pancreas 1993;8:638-46.

37 Lerch MM, Halangk W, Kruger B. The role of cysteine proteases in intracellular pancreatic serine protease activation. Adv Exp Med Bio 2000;477:403-11.

38 Weis S, Shintani S, Weber A, et al. Src blockade stabilizes a Flk/cadherin complex, reducing edema and tissue injury following myocardial infarction. $J$ Clin Invest 2004;1 13:885-94.

39 Engelhardt B, Wolburg H. Mini-review: Transendothelial migration of leukocytes: through the front door or around the side of the house? Eur J Immunol 2004;34:2955-63.

40 Takeda H, Nagafuchi A, Yonemura S, et al. V-src kinase shifts the cadherinbased cell adhesion from the strong to the weak state and beta catenin is not required for the shift. J Cell Biol 1995;131:1839-47.

41 Daniel JM, Reynolds AB. Tyrosine phosphorylation and cadherin/catenin function. Bioessays 1997; 19:883-91.

42 Fuchs $M$, Wang $H$, Ciossek T, et al. Differential expression of MAM-subfamily protein tyrosine phosphatases during mouse development. Mech Dev 1998;70:91-109

43 Brady-Kalnay SM, Mourton T, Nixon JP, et al. Dynamic interaction of PTPmu with multiple cadherins in vivo. J Cell Biol 1998;141:287-96.

44 Brady-Kalnay SM, Flint AJ, Tonks NK. Homophilic binding of PTP mu, a receptor-type protein tyrosine phosphatase, can mediate cell-cell aggregation. J Cell Biol 1993;122:961-72.

45 Zondag GC, Koningstein GM, Jiang YP, et al. Homophilic interactions mediated by receptor tyrosine phosphatases mu and kappa. A critical role for the novel extracellular MAM domain (published erratum appears in J Biol Chem 1995 ;270: 24621), J Biol Chem 1995;270:14247-50.

46 Pei D, Neel BG, Walsh CT. Overexpression, purification, and characterization of SHPTP1, a Src homology 2-containing protein-tyrosine-phosphatase. Proc Natl Acad Sci U S A 1993:90:1092-6.

47 Zhao Z, Larocque R, Ho WT, et al. Purification and characterization of PTP2C, a widely distributed protein tyrosine phosphatase containing two $\mathrm{SH} 2$ domains. J Biol Chem 1994;269:8780-5.

48 Kevil CG, Okayama N, Alexander JS. H(2)O(2)-mediated permeability II: importance of tyrosine phosphatase and kinase activity. Am J Physiol Cell Physiol 2001;281:C1940-7.

49 Akhtar $\mathrm{N}$, Hotchin NA. RACl regulates adherens junctions through endocytosis of E-cadherin. Mol Biol Cell 2001;12:847-62.

50 Meda $\mathbf{P}$, Bruzzone R, Chanson $M$, et al. Gap junctional coupling modulates secretion of exocrine pancreas. Proc Natl Acad Sci U S A 1987;84:4901-4

51 Orci L, Ravazzola M. Anderson RG. The condensing vacuole of exocrine cells is more acidic than the mature secretory vesicle. Nature 1987;326:77-9.

52 Bruzzone R, Halban PA, Gjinovci A, et al. A new, rapid, method for preparation of dispersed pancreatic acini. Biochem J 1985;226:621-4

53 Williams JA. Effects of cytochalasin B on pancreatic acinar cell structure and secretion. Cell Tissue Res 1977;179:453-66. 